\title{
Characterizing Sorption and Permeation Properties of Membrane Filters Used for Aquatic Integrative Passive Samplers
}

\section{Satoshi Endo, Yunosuke Matsuura}

\begin{tabular}{|c|l|}
\hline Citation & Environmental Science \& Technology, 52(4); 2118-2125 \\
\hline Issue Date & 2018-01-25 \\
\hline Type & Journal Article \\
\hline Textversion & author \\
\hline Right & $\begin{array}{l}\text { This document is the Accepted Manuscript version of a Published Work that appeared in } \\
\text { final form in Environmental Science \& Technology, copyright C American Chemical } \\
\text { Society after peer review and technical editing by the publisher. To access the final edited } \\
\text { and published work see } \text { https://doi.org/10.1021/acs.est.7b05144 }\end{array}$ \\
\hline URI & http://dlisv03.media.osaka-cu.ac.jp/il/meta_pub/G0000438repository_15205851-52-4-2118 \\
\hline DOI & 10.1021/acs.est.7b05144 \\
\hline
\end{tabular}

SURE: Osaka City University Repository http://dlisv03.media.osaka-cu.ac.jp/il/meta_pub/G0000438repository

ENDO S., \& MATSUURA Y. (2018). Characterizing Sorption and Permeation Properties of Membrane Filters Used for Aquatic Integrative Passive Samplers. Environmental Science and Technology. 52, 2118-2125. 
1 Characterizing Sorption and Permeation Properties of

2. Membrane Filters Used for Aquatic Integrative Passive

3

4

5

6

7 8 Japan

9

10

11

12

satoshi.endo@eng.osaka-cu.ac.jp

*Corresponding author:

Phone/Fax: ++81-6-6605-2763

\section{Samplers}

Satoshi Endo, ${ }^{1,2,}{ }^{*}$ Yunosuke Matsuura ${ }^{2}$

1 Urban Research Plaza, Osaka City University, Sugimoto 3-3-138, Sumiyoshi-ku, 558-8585 Osaka, Japan

2 Graduate School of Engineering, Osaka City University, Sugimoto 3-3-138, Sumiyoshi-ku, 558-8585 Osaka,

13

14 
15 TOC art

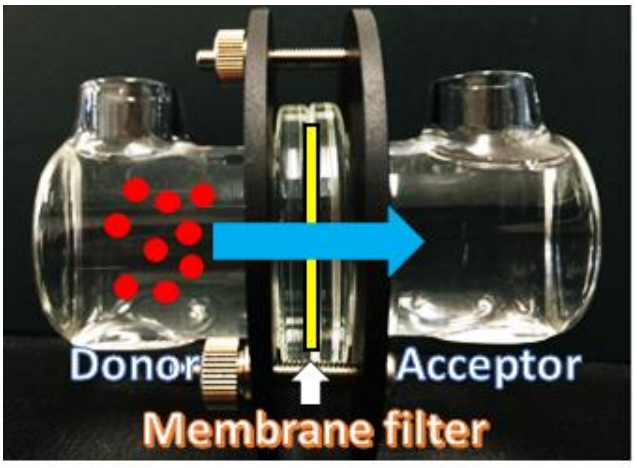


Aquatic integrative passive sampling is a promising approach to measure the time-weighted average concentration, yet our understanding for the sampling mechanisms of polar organic contaminants should be

20 further advanced to fully exploit the potential of the method for real-world applications. This study aimed to

21 characterize the sorption and permeation properties of polyethersulfone (PES) and poly(tetrafluoroethylene)

22 (PTFE) membrane filters (MFs) used for passive samplers. Batch sorption experiments with 14 probe

23 chemicals showed that the sorption by PES was generally strong, with the respective sorption coefficients

24 greater than the octanol-water partition coefficients by 2-3 log units. In contrast, the PTFE filter exhibited no 25 significant sorption for all tested chemicals, representing a promising candidate MF that avoids lag-times and 26 slow responses to fluctuating concentrations. Permeation experiments in a glass cell system and successive 27 modeling demonstrated that, if no sorption to the MF occurs, the MF permeation of a chemical can be fully 28 described with a first-order model that considers the transfer through the aqueous boundary layers and the 29 diffusion in water-filled MF pores. Significant sorption to the MF coincided with substantial delay of 30 permeation, which was successfully modeled with the local sorption equilibrium assumption. These findings 31 have implications for improved sampler configurations and successful models for the chemical uptake.

33 Keywords: Integrative passive sampler, membrane filter, permeation, sorption, diffusion 
Aquatic integrative passive sampling methods have received increasing attention from

environmental scientists over the last decades ${ }^{1-4}$ Among strong advantages of integrative passive sampling is its potential to provide time-weighted average (TWA) concentrations at low cost and with a relatively small effort. TWA concentrations are more representative and more relevant for ecotoxicological risks associated with the contaminants of concern than spot concentrations measured by grab sampling. Active research is ongoing to evaluate and improve the accuracy and reliability of the methods ${ }^{2,4}$ and to extend the measurement concept to further chemicals, ${ }^{5-7}$ sampling environments, ${ }^{8}$ and purposes. ${ }^{9-11}$

The most widely used integrative samplers today for polar organic contaminants may be Polar Organic Contaminants Integrative Samplers (POCIS) ${ }^{12}$ and Chemcatcher. ${ }^{13}$ Both POCIS and Chemcatcher comprise of sorbent, a membrane filters (MF), and a body of the sampler that holds the former two. The sorbent (e.g., OASIS HLB, Empore SDB disk) serves as the sink of monitored chemicals and will be subjected to chemical analysis in the end. The MF (or MFs) physically hold the sorbent and protect it from physical damages, particle adhesion, and biofouling. The MFs also serve to regulate the chemical uptake by the sampler, as chemicals in water have to permeate through the MF(s) before sorbing to the sorbent.

$R_{\mathrm{s}}$ is "the theoretical volume of water sampled by the sorbent per time" and is equal to "the rate of increase in the chemical amount sorbed by the sorbent" divided by "the external aqueous phase concentration". Thus, in theory, the TWA concentration is calculated as,

$$
\frac{\int_{0}^{t} C_{w} d t}{t}=\frac{m_{s}}{t R_{S}}
$$

The left-hand side of eq 1 is the TWA concentration, $t[\mathrm{~d}]$ is the deployment time, $m_{\mathrm{s}}[\mathrm{mg}]$ is the measured amount in the sorbent, and $C_{\mathrm{w}}[\mathrm{mg} / \mathrm{L}]$ is the external aqueous phase concentration. Under constant $C_{\mathrm{w}}$ conditions, eq 1 can be simplified to, 
61 Thus, $m_{\mathrm{s}}$ should linearly increase with time. Equation 2 is also used to calibrate $R_{\mathrm{s}}$ experimentally, based on data measured in a controlled laboratory condition with known $C_{\mathrm{w}}$.

For using aquatic integrative samplers to measure a broad range of polar organic contaminants, however, three major obstacles appear to exist. First, the chemical uptake behavior often does not follow eqs 1 and 2. Experimental data show that a slightly curvy uptake can occur even well below the sorption equilibrium. ${ }^{14,15}$ Moreover, chemicals with relatively hydrophobic nature can exhibit substantial lag-times

67 (i.e., delays of increase of $m_{s}$ in the early time of sampling) because of their significant sorption to the

MF. ${ }^{9,14,16-19}$ Indeed, various chemicals have been detected in the MF in substantial amounts, sometimes even more than in the sorbent. ${ }^{13,14,18,20}$ The sorption to the MF can also cause slow responses to fluctuating aqueous phase concentrations,,$^{21,22}$ which violates a condition of eq 1 . The second issue is that, even if eqs 1 and 2 hold true, the value of $R_{\mathrm{s}}$ has to be known to convert the measured $m_{\mathrm{s}}$ to the TWA concentration. $R_{\mathrm{s}}$ depends on the chemicals and the sampler configurations and is also influenced by the external environmental conditions such as the flow regime around the sampler. Various methods are available for experimental determination of $R_{\mathrm{s}}$, although all are laborious to varying degrees. ${ }^{2} \mathrm{~A}$ model to predict $R_{\mathrm{s}}$ for given chemicals, samplers, and environmental conditions does not exist so far, despite the fact that there have been some attempts to predict $R_{\mathrm{s}}$ from empirical correlation approaches. ${ }^{23,24}$ The third problem is the absence of a field-correction method for POCIS and Chemcatcher, such as performance reference compounds for hydrophobic passive samplers, because the uptake and release of chemicals are not simply isotropic in many cases. ${ }^{14,25,26}$ Clearly, better understanding is needed for the sampling mechanisms to achieve linear uptake, avoid significant lag-times, establish general $R_{\mathrm{s}}$ prediction models, and develop fieldcorrection methods for a wider range of chemicals. this end, we performed batch sorption experiments and permeation experiments using isolated MFs (not the whole samplers). Poly(ethersulfone) (PES) and poly(tetrafluoroethylene) (PTFE) MFs were used in this work. 
The former is the current standard MF for POCIS and Chemcatcher when polar contaminants are targeted..$^{2,4}$

Various neutral and ionic chemicals were used as probes. The results of permeation experiments were

analyzed using mathematical models. While an ever increasing number of studies report determination of $R_{\mathrm{s}}$

and field applications of aquatic passive samplers, the diffusive permeation behavior of chemicals through

isolated MFs has not been investigated in the existing studies. The outcomes of this study should provide

useful insights into the sampling mechanisms of POCIS, Chemcatcher, and any analogous sampler.

\section{1}

\section{Materials and Methods}

Materials. PES filters (Supor 100 Membrane Disc Filter, $0.1 \mu \mathrm{m}$ pore size, $132 \mu \mathrm{m}$ thickness, Pall Corporation, NY, US) pre-cleaned with methanol were obtained from EST-Lab (St. Joseph, MO, US). This specific type is among the most frequently used PES filters in previous studies. $5,9,12,14,15,18$ Hydrophilic PTFE filters (Omnipore, $0.1 \mu \mathrm{m}$ pore size, $30 \mu \mathrm{m}$ thickness) were purchased from Millipore. HPLC grade methanol was obtained from Wako Pure Chemicals (Osaka, Japan) and acetonitrile from Sigma-Aldrich Japan (Tokyo). Chemicals that used as solute were purchased from Tokyo Chemical Industry (Tokyo, Japan), Sigma-Aldrich Japan, and Wako Pure Chemicals. Glassware was rinsed with methanol or heated at $450^{\circ} \mathrm{C}$ for $4 \mathrm{~h}$ to remove organic residues.

All experiments described in the following were conducted with water purified with a Millipore Direct Q3 Water Purification System. For ionizable chemicals, buffer solution (pH 7.5) containing $5 \mathrm{mM} \mathrm{CaCl}_{2}$ and $2 \mathrm{mM}$ Tris was used instead of pure water for both sorption and permeation experiments to control pH and ionic strength.

Batch sorption experiments. To investigate the kinetic and equilibrium sorption properties of the MFs, batch sorption experiments were performed using 14 chemicals (Table 1). Out of these, 9 chemicals are $>99 \%$ neutral, 2 chemicals are $>99 \%$ anionic, and 2 chemicals are $>98 \%$ cationic at $\mathrm{pH}$ 7.5. Umbelliferone $\left(\mathrm{p} K_{\mathrm{a}}, 7.78\right)^{27}$ is partially (33\%) anionic at $\mathrm{pH} 7.5$ and is classified into neutral compounds here. Table S1 in the Supporting Information (SI), SI-1, summarizes $\mathrm{p} K_{\mathrm{a}}, \log K_{\mathrm{ow}}$, and $\log D_{\mathrm{ow}}$ calculated for $\mathrm{pH}$ 7.5. These probe 
chemicals were selected on the basis of functional group diversity, hydrophobicity, and analytical possibilities, but not environmental relevance. Methanolic stock solutions were further diluted with water

111 (or buffer) to make test solutions. The final methanol content was $<0.04 \%(\mathrm{v} / \mathrm{v})$. PES and PTFE filters were 112 cut into pieces of $1 \times 1$ or $1 \times 2 \mathrm{~cm}^{2}$. One or two pieces (ca 5-20 mg in total) were weighed into 5-20 mL vials 113 and sonicated once in methanol and at least twice in water (or buffer) for 5 min each in order to clean the 114 MF and remove residual air from the pores. After sonication, water was removed from the vial using a nonequilibrium. If $K_{\mathrm{PES} / \mathrm{w}}$ at $48 \mathrm{~h}>K_{\mathrm{PES} / \mathrm{w}}$ at $24 \mathrm{~h}$ by $>10 \%$, additional experiments for $96 \mathrm{~h}(4 \mathrm{~d})$ and $168 \mathrm{~h}(7 \mathrm{~d})$ were conducted. Duplicate vials were prepared for each sampling time for PES, which mostly resulted in a difference of less than a few percent in $K_{\mathrm{PES} / \mathrm{w}}$. For PTFE, only $24 \mathrm{~h}$ tests were performed, mostly in duplicates equation, 
134 where $C_{\mathrm{MF}}[\mathrm{mg} / \mathrm{kg}]$ and $C_{\mathrm{w}}[\mathrm{mg} / \mathrm{L}]$ are the measured concentrations in the MF and water, respectively, and $n_{\mathrm{Fr}}$

$135[-]$ and $K_{\mathrm{Fr}}\left[(\mathrm{mg} / \mathrm{kg}) /(\mathrm{mg} / \mathrm{L})^{\mathrm{nFr}}\right]$ are the Freundlich exponent and coefficient, respectively. These isotherm experiments were performed with a fixed shaking time of $24 \mathrm{~h}$.

Permeation experiments. Permeation experiments were conducted using a custom-made glass permeation cell unit (see the graphical abstract of this article). The permeation cell unit consists of two halfcells that are identical in shape and have a large opening (30 $\mathrm{mm}$ i.d.) on the side. The MF was cut into a round piece slightly larger than the opening size, conditioned with methanol and water, and was sandwiched propylene glycol, $\gamma$-cyclodextrin). For these chemicals, the initial concentration was raised up to $200 \mathrm{mg} / \mathrm{L}$, because of the low sensitivity of the instrument. In addition, for the TOC-measured chemicals, each cell had 
three replicate cell units were prepared for a single run, and at least two runs were performed, which resulted in at least 6 data points in total for each chemical and MF. A longer-term permeation experiment up to $36 \mathrm{~h}$ was additionally conducted for indole permeating through the PES filter.

We note that the system of the permeation experiment is not intended to mimic real environmental conditions. In fact, the donor phase concentration in our system decreases throughout as the result of the mass transfer toward the acceptor. We however stress that, by analyzing the data using mechanisticallybased models, it is possible to achieve general conclusions regarding permeation of chemicals through MFs, as shown below.

Modeling the results of permeation experiments. The permeation experiments were simulated with two mathematical models. Both models consider the transfer of chemicals through the two aqueous boundary layers (ABLs) in the direct vicinity of the MF and the diffusion through the water-filled pores of the MF. Model details are provided in the $\mathrm{SI}(\mathrm{SI}-3)$, and thus the description here is only brief.

The first model simulates the cases where the sorption of the chemical to the MF is negligible.

Assuming the steady-state mass transfer through the two ABLs and the MF, the concentration change in the donor side solution can be described by the following first-order equation,

$$
V \frac{d C_{d o n}}{d t}=-k\left(C_{d o n}-C_{a c c}\right)
$$

where $V\left[\mathrm{~m}^{3}\right]$ is the volume of the solution in the donor cell, which is equal to that in the acceptor cell, $C_{\text {don }}$ and $C_{\text {acc }}[\mathrm{mg} / \mathrm{L}]$ are the concentrations in aqueous solution of the donor and acceptor half-cells, respectively, and $k\left[\mathrm{~m}^{3} / \mathrm{s}\right]$ is the overall mass transfer coefficient. From the mass conservation, " $C_{\text {don }}+C_{\text {acc }}$ " is equal to the initial donor concentration $C_{\text {don, }, 0}$ at any time. Hence, by solving eq 4 , we obtain,

$$
C_{d o n}=\frac{C_{d o n, 0}}{2}\left(1+e^{-\frac{2 k}{V} t}\right), C_{a c c}=\frac{C_{d o n, 0}}{2}\left(1-e^{-\frac{2 k}{V} t}\right)
$$

Equation 5 can be fitted to the results of permeation experiments with $k$ being the adjustable parameter. As $k$ is the reciprocal of the sum of mass transfer resistances posed by the two ABLs and the MF, it can be 
related to the aqueous diffusion coefficient $\left(D_{\mathrm{w}}\left[\mathrm{m}^{2} / \mathrm{s}\right]\right)$, the area of the opening of the half-cells $\left(A\left[\mathrm{~m}^{2}\right]\right)$, the thickness of the ABLs $\left(d_{\mathrm{ABL}}[\mathrm{m}]\right)$, and the porosity $(\varepsilon[-])$, the tortuosity $(\tau[-])$ and the thickness $\left(d_{\mathrm{MF}}[\mathrm{m}]\right)$ of the MF (see SI-3). Of these parameters, $D_{\mathrm{w}}, A, \varepsilon$, and $d_{\mathrm{MF}}$ are known or can reasonably be estimated. $\tau$ is difficult to estimate and was set to 1.3 here as an initial guess for both MFs. The validity of this will be discussed below. $d_{A B L}$ was estimated with permeation data, as shown later.

\section{Results and Discussion} appear to have reached apparent equilibrium within $24 \mathrm{~h}$ (i.e., apparent $K_{\mathrm{PES} / \mathrm{w}}$ at $48 \mathrm{~h}=$ apparent $K_{\mathrm{PES} / \mathrm{w}}$ at 24 $\mathrm{h}$ within $10 \%$ difference, as defined in the method section). The other six chemicals, namely 2 methoxynaphthalene, 1-cyanonaphthalene, 1-naphthaleneacetamide, caffeine, propranolol, and tryptamine showed a gradual decrease in the aqueous phase concentration (i.e., increase in apparent $K_{\mathrm{PES} / \mathrm{w}}$ ) over $7 \mathrm{~d}$ (Figures S1, S2). In the Supporting Information SI-4, we explain our modeling efforts to reproduce and understand this slow equilibration. In brief, the slow equilibration of two chemicals with the highest $K_{\text {PES } / w}$ (2methoxynaphthalene, 1-cyanonaphthalene) can be well explained by the diffusion in filter pores that is strongly retarded by the sorption to PES matrix. For the other four chemicals, however, it is not clear why the equilibration needs $>7 \mathrm{~d}$. Particularly, the slow sorption behavior of caffeine, a relatively hydrophilic neutral chemical, cannot be explained by our model. We extracted the PES filters after the $7 \mathrm{~d}$ sorption experiment (duplicate) with acetonitrile and obtained 99 and $101 \%$ recovery, indicating reversible sorption 
of caffeine by PES. We speculate that slow absorption (diffusion) into the PES polymer matrix occurs and becomes rate-limiting for relatively large chemicals, causing slow equilibration in batch experiments. That said, more work is clearly necessary for elucidating the actual mechanisms.

Sorption isotherms for PES filter. The sorption isotherms to the PES filter were measured for 4 neutral, 2 anionic, and 2 cationic organic chemicals with a sorption time of $24 \mathrm{~h}$ (Figure 1). Note that, as

212 shown above, $24 \mathrm{~h}$ was not sufficient to reach equilibrium for some chemicals (2-methoxynaphthalene, 213 propranolol, tryptamine here), but we still show the results of these chemicals in Figure 1 as additional 214 information. All measured isotherms follow the Freundlich model (eq 3). The Freundlich exponent $\left(n_{\mathrm{Fr}}\right)$ was 215 from 0.74 to 0.95 (Table 1 ), indicating moderately nonlinear to linear isotherms. To our knowledge, nonlinear sorption isotherms from water to PES filters have not been shown before. Isotherm nonlinearity suggests that $K_{\mathrm{PES} / \mathrm{w}}$ should be measured at a field-relevant concentration to obtain useful results. Moreover, since nonlinear sorption is nothing but occurrence of self-competition at sorption sites (i.e., molecules of the single chemical compete with each other), it is expected that competitive sorption between multiple solutes could also occur.

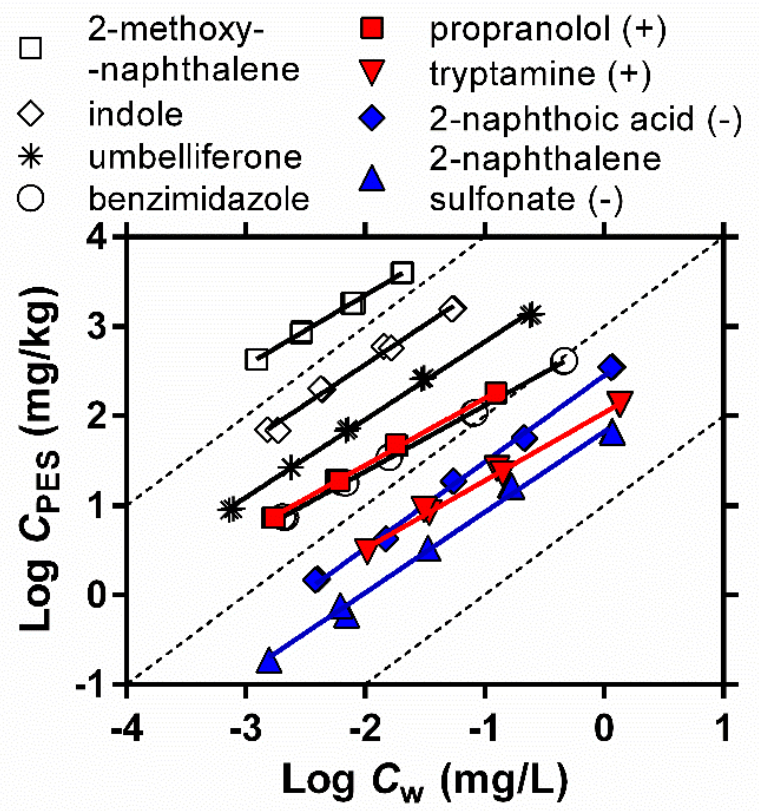


Figure 1. Sorption isotherms for PES filter. Solid lines indicate the Freundlich model fit. Dashed lines indicate a slope of 1 (i.e., linear isotherms). (+) and (-) are cationic and anionic chemicals, respectively. The sorption time was $24 \mathrm{~h}$.

$K_{\mathrm{PES} / \mathrm{w}}$ for neutral chemicals. To compare the sorption strength of the PES filter across chemicals, $K_{\mathrm{PES} / \mathrm{w}}$ values were plotted against $K_{\mathrm{ow}}$ (Figure 2). For the six chemicals that showed slow equilibration, the apparent $K_{\mathrm{PES} / \mathrm{w}}$ values measured at $7 \mathrm{~d}$ were used. All values used are given in Table 1 . Values of $K_{\mathrm{PES} / \mathrm{w}}$ for neutral chemicals are $\sim 2.5$ log units larger than those of $K_{\text {ow }}$, showing strong sorption properties of the PES filter. Although significant sorption by the PES filter has been noted before with, e.g., pesticides, ${ }^{14,16}$ alkylphenols, ${ }^{18}$ and estrogens, ${ }^{20}$ such strong sorption by PES in comparison to $K_{\text {ow }}$ has not been pointed out. Interestingly, some researchers in another research field do recognize the strong sorption by PES and even advocated a deliberate use of PES filters for removal of organic contaminants from water. ${ }^{28,29}$

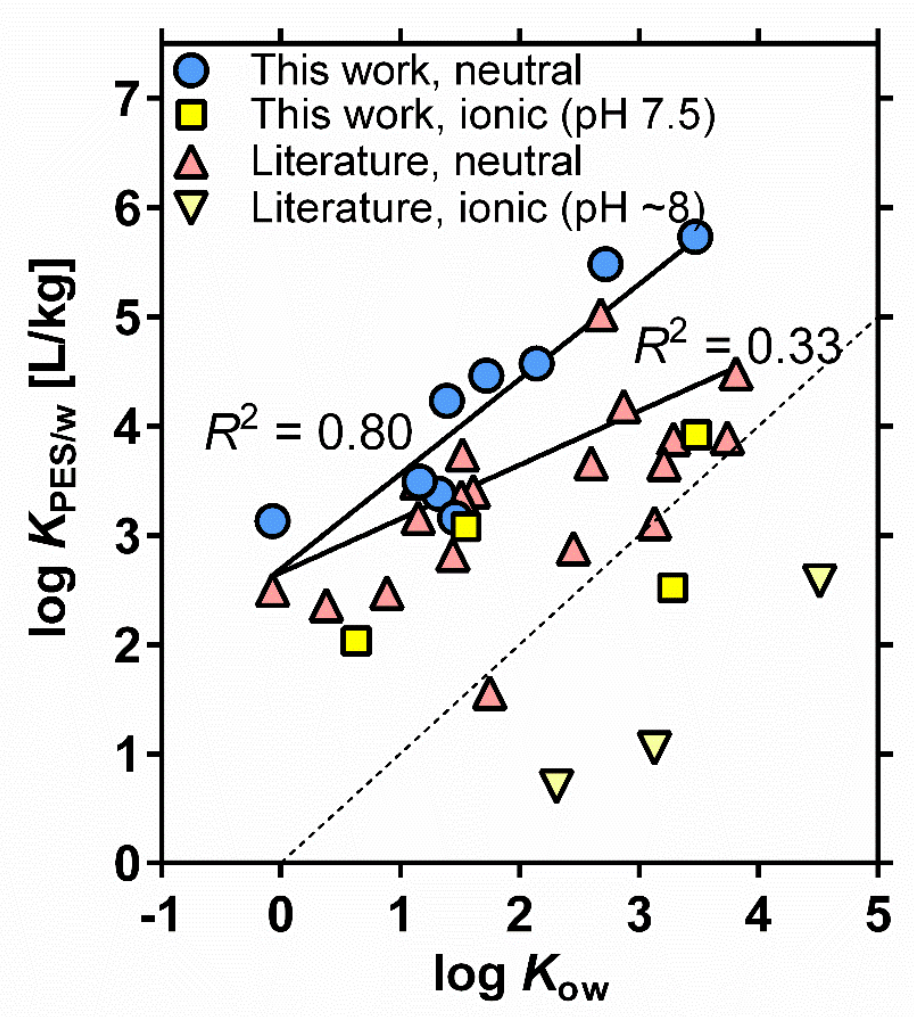


A high $K_{\mathrm{PES} / \mathrm{w}}$ value implies the possible occurrence of significant lag phases when the PES filter is used for aquatic integrative passive samplers. According to ref 14 , a substantial lag-time ( $>5 \mathrm{~d})$ can occur when $\log K_{\mathrm{PES} / \mathrm{w}}>3$. As shown, the measured log $K_{\mathrm{PES} / \mathrm{w}}$ for all 10 neutral chemicals in this work are $>3$. While the actual lag-time depends also on the other sampling conditions, generally high $K_{\mathrm{PES} / \mathrm{w}}$ values suggest that lag-times can occur to many chemicals. work (Figure 2). However, the correlation becomes substantially poorer if the data from Vermeirssen et al. ${ }^{14}$ are combined. The log $K_{\mathrm{PES} / \mathrm{w}}$ values from this work tend to be higher than those from the literature ${ }^{14}$ in the $\log K_{\mathrm{PES} / \mathrm{w}}-\log K_{\mathrm{ow}}$ plot. Three possible reasons for the observed differences can be offered. First and most importantly, PES and octanol have totally different molecular structures, and they may well undergo $254 K_{\mathrm{PES} / \mathrm{w}}$ and $\log K_{\mathrm{ow}}$. Thus, the choice of chemicals largely influences the log $K_{\mathrm{PES} / \mathrm{w}}-\log K_{\mathrm{ow}}$ plot. There is only one chemical common in both studies (caffeine), and the reported log $K_{\mathrm{PES} / \mathrm{w}}$ is only minorly (0.6 log units) higher in this work than the literature. Second, the sorption isotherm nonlinearity and competition might 257 explain the observations, yet only to a minor extent, because the observed isotherm nonlinearity by the PES 258 filter is only moderate (Figure 1). Third, many chemicals used in ref 14 are pesticides and pharmaceuticals and are larger in molecular size than the chemicals used in this work. Possibly, an equilibration time of one week adopted in ref 14 was not long enough to closely approach the true equilibrium $K_{\mathrm{PES} / \mathrm{w}}$ for some of their chemicals. In any case, the results shown in Figure 2 clearly tell us that estimation of $K_{\mathrm{PES} / \mathrm{w}}$ via $K_{\text {ow }}$ can cause substantial errors.

We attempted to fit the polyparameter linear free energy relationships (PP-LFERs) with Abraham's descriptors ${ }^{30,31}$ to the $K_{\mathrm{PES} / \mathrm{w}}$ data for neutral compounds, which resulted in a relatively poor fit $\left(R^{2}, 0.69 ; \mathrm{SD}\right.$, 0.54; see SI-5 for details). Possible reasons for this result include nonattainment of equilibrium, a mixed mode of adsorption and absorption, and nonlinear sorption isotherms. ${ }^{31}$ 
The strong sorption by PES for a range of compounds may be explained by its molecular structure

with phenyl and sulfonate groups. The former offers a desirable hydrophobic molecular environment to the sorbing chemicals, while the latter can undergo strong polar interactions. In addition, a high surface area of the porous filter may be a contributing reason for high $K_{\mathrm{PES} / \mathrm{w}}$, provided that the mode of sorption is surface adsorption.

$K_{\mathrm{PES} / \mathrm{w}}$ for ionic chemicals. The sorption of ionic chemicals to the PES filter was generally weaker than

273 that of neutral chemicals (Figure 2). Nevertheless, it is notable that the sorption was always significant and

274 measurable, and that the values of $K_{\mathrm{PES} / \mathrm{w}}$ for ionic chemicals are comparable to $K_{\mathrm{ow}}$ of their neutral species.

$275 K_{\mathrm{PES} / \mathrm{w}}$ was measurable even for 2-naphthalene sulfonate, which is present entirely as ion at around neutral $\mathrm{pH}$. These results further demonstrate the relatively strong sorption properties of the PES filter. In the SI, a plot for $\log K_{\mathrm{PES} / \mathrm{w}}$ against $\log D_{\text {ow }}$ is provided as additional information (Figure S3).

No sorption to PTFE filter. In contrast to the PES filter, the sorption by the PTFE filter was negligibly weak for all chemicals we studied; that is, the final aqueous phase concentration in the batch with the PTFE filter was $94-101 \%$ of the initial concentrations. These percentages were just similar to those of the controls without filter (Table S5). From these results and the solid-to-liquid ratio adapted in the experiments, the PTFE-water partition coefficients ( $K_{\text {PTFE } / \text { water }}$ ) should be $<45 \mathrm{~L}_{\text {water }} / \mathrm{kg}_{\text {PTFE }}(<1.65$ on the log scale) for all studied chemicals. These results were obtained only in a single experimental condition (one concentration level, $24 \mathrm{~h}$ equilibration time), but we did not make a further attempt to measure $K_{\text {PTFE/water }}$ accurately, as the sorption is evidently weak. Considering the fact that the sorption to the MF is generally an undesirable feature that can cause a lag-time and/or a slow response to the fluctuating concentration in the field applications, we conclude that PTFE is a more advantageous filter material than PES for aquatic integrative passive samplers. According to the recent comprehensive reviews for $\mathrm{POCIS}^{2}$ and Chemcatcher, ${ }^{4}$ vast majority of the previous studies used PES filters, and these reviews even do not mention the use of an inert filter such as PTFE. To our membrane for aquatic integrative passive samplers. ${ }^{13}$ 
Permeation of nonsorptive chemicals. In permeation experiments with the nonsorptive tracers, the 293 decrease in concentration in the donor cell corresponded well to the increase in concentration in the 294 acceptor cell (Figure 3A, B). The sum of the solute masses in donor and acceptor cells at each sampling time 295 was $98 \pm 5 \%$ (mean \pm SD, range: $84-112 \%$ ) of the initial mass added to the donor cell, indicating no 296 significant loss process including sorption to the MF. The first-order mass transfer model was fitted to the 297 results with $k$ being the fitting parameter. The obtained values of $k$ for both PES and PTFE were in the order 298 of thiourea $>1,2$-propylene glycol $>$ glucose $>\gamma$-cyclodextrin and were correlated with $D_{\mathrm{w}}$ of these chemicals 299 (Figure 4; see Table S6 for $k$ and $D_{\mathrm{w}}$ values). These correlations suggest that the mass transfer through the 300 MFs is governed by aqueous diffusion. The $k$ values for PTFE are higher than those for PES, agreeing with the 301 fact that the used PTFE filter is thinner than the PES filter (30 vs $132 \mu \mathrm{m}$, respectively). 
Nonsorptive chemicals
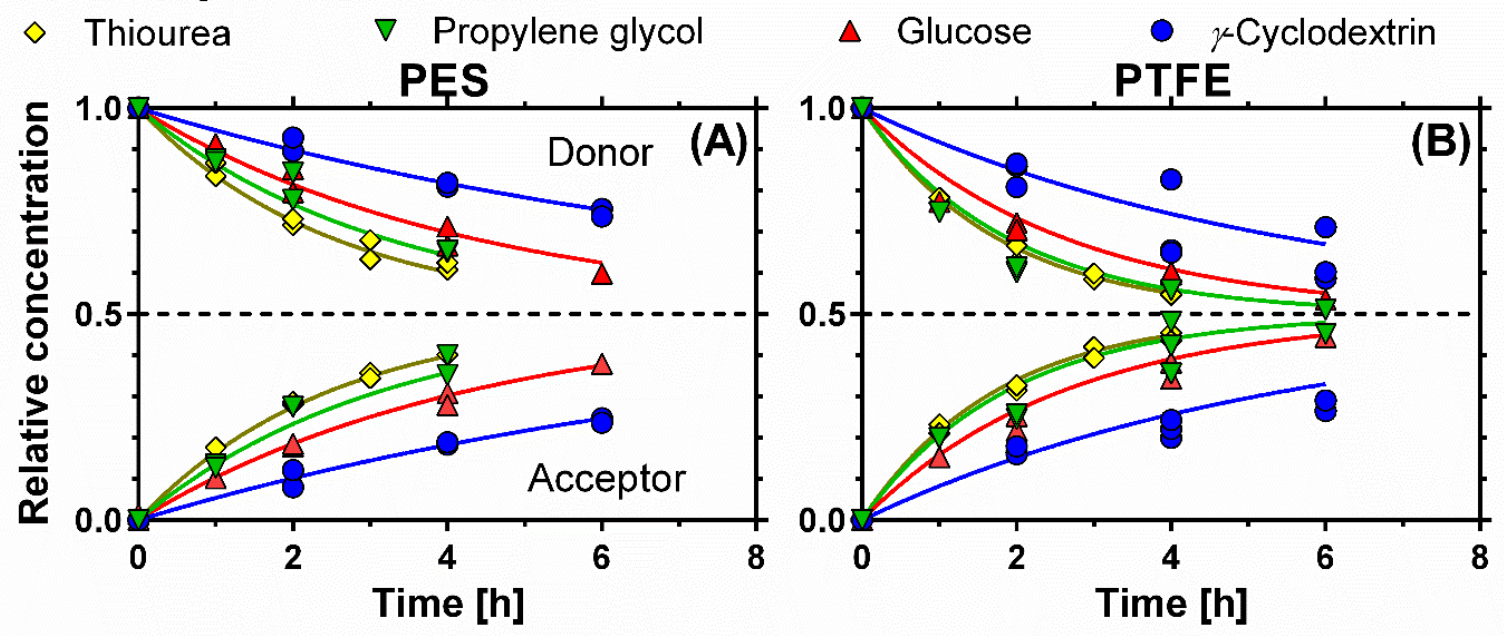

\section{Sorptive chemicals}

$\bigcirc$ 2-Naphthalene sulfonate $\square$ Benzimidazole $\nabla$ Indole $\Delta$ 2-Methoxynaphthalene
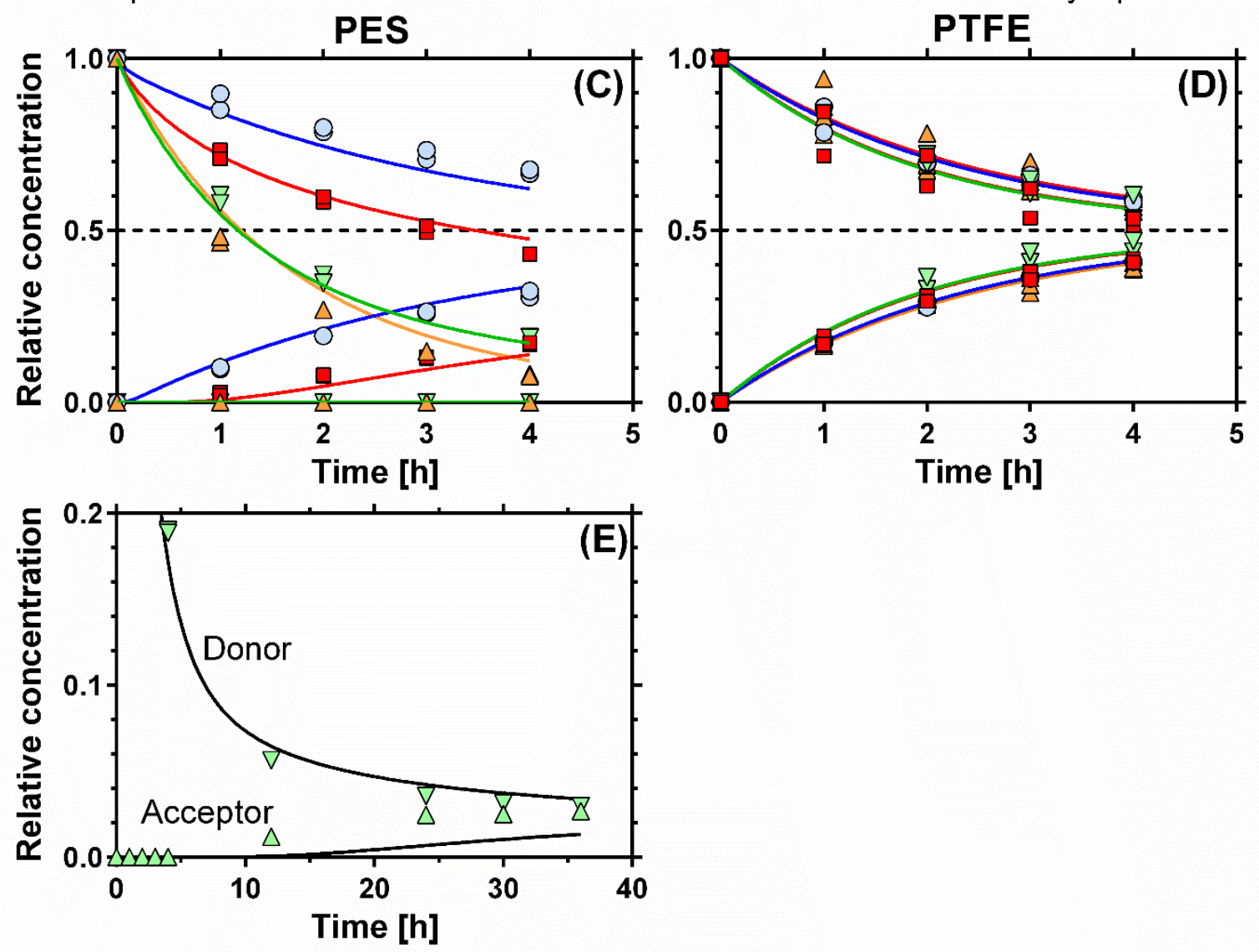

Figure 3. Results of permeation experiments for nonsorptive chemicals (A, B) and sorptive chemicals (C, D) through PES and PTFE filters. Panel E shows the permeation of indole through the PES filter over $36 \mathrm{~d}$. The vertical axis indicates the concentration relative to the initial concentration in the donor cell. Symbols are explained in the figure. In panels $A, B$, and $D$, lines show the fitted first-order mass transfer model. In panels $C$ and $E$, lines indicate the results of numerical modeling (see text). 


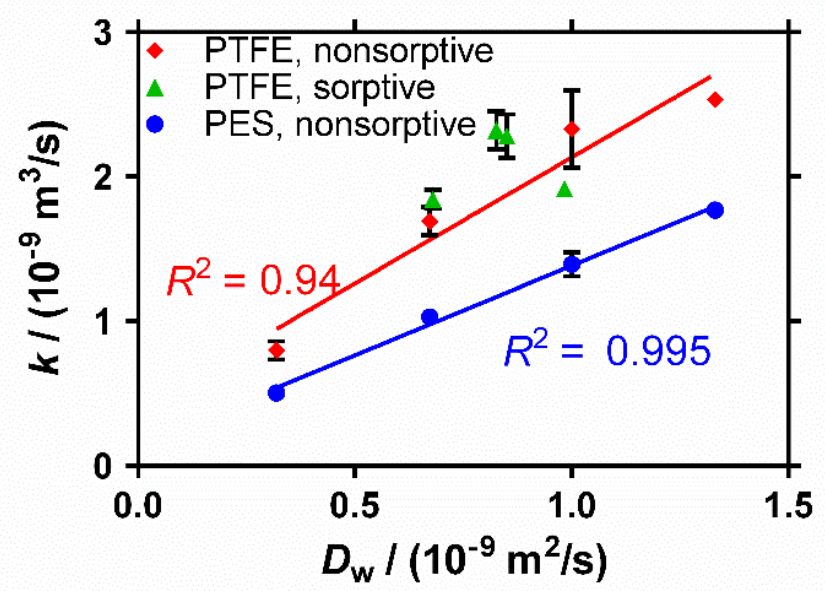

Figure 4. Mass transfer coefficients $(k)$ for MF permeation vs aqueous diffusion coefficients $\left(D_{w}\right)$ for 310 sorptive and nonsorptive chemicals. The lines show the linear regressions for the nonsorptive chemicals. The error bars indicate the standard errors (not shown if smaller than the symbols).

Using the permeation data for the nonsorptive chemicals, $d_{\mathrm{ABL}}$ was estimated (see eqs $\mathrm{S} 3$ and $S 4$ in

the SI). The best estimate that minimizes the sum of the squared residuals was $88 \mu \mathrm{m}$ for PES and $122 \mu \mathrm{m}$

for PTFE on each side of the filter. These values are well in line with typical ABL thickness in flowing water

(ref 32, p 277; refs 1,33). Using these $d_{\mathrm{ABL}}$, the contributions of the ABLs and the MF to the overall mass

transfer resistance can be estimated (eq S3 in the SI); they were $35 \%$ by the ABLs and $65 \%$ by the MF for PES and $79 \%$ by the ABLs and $21 \%$ by the MF for PTFE. Here, three additional remarks should be stated. First, the obtained values for $d_{A B L}$ are not independent of the other membrane-related parameters used. Particularly uncertain is the tortuosity $\tau$. Use of a higher value for $\tau$ would result in a lower value for $d_{A B L}$, and vice versa. For PES, additional support for $d_{\mathrm{ABL}}=88 \mu \mathrm{m}$ and $\tau=1.3$ will be provided below. Second, it is known that the mass transfer through an $\mathrm{ABL}$ is actually proportional to $D_{\mathrm{w}}{ }^{2 / 3}$ instead of $D_{\mathrm{w}} \cdot{ }^{32}$ Indeed, the $k$ values obtained through the MFs for chemicals with $D_{\mathrm{w}}$ of $0.3-1.3 \times 10^{-9} \mathrm{~m}^{2} / \mathrm{s}$, covering most of the organic contaminants of 
tracer chemicals. Hence, although a good mass balance was obtained and the results are reasonable, we cannot totally exclude the possibility that these chemicals partially transformed to other chemicals during the experiment.

Permeation of sorptive chemicals. The permeation behavior of the sorptive chemicals through the PES filter was considerably different from that of the nonsorptive chemicals (Figure 3C, E). The concentration in the donor cell decreased faster and that in the acceptor cell increased slower, as compared to the nonsorptive chemicals. The mass balance was not maintained, indicating the significance of the sorption to the PES filter. The rate of concentration decrease/increase appears to be related to $K_{\mathrm{PES} / \mathrm{w} \text {; }}$ that is, the higher the $K_{\mathrm{PES} / \mathrm{w}}$ value, the faster the concentration decrease in the donor, and the slower the concentration increase in the acceptor. Particularly, indole and 2-methoxynaphthalene, the two strongly sorbing chemicals tested in this permeation experiment, were not detectable in the acceptor cell within $4 \mathrm{~h}$. The longer term experiment conducted with indole did show the appearance of this chemical in the acceptor cell after $12 \mathrm{~h}$, demonstrating a breakthrough of this chemical (Figure 3E).

In contrast to the PES filter, the permeation behavior of the four sorptive chemicals through the PTFE filter was similar to that of the nonsorptive chemicals (Figure 3D). This result can be expected, as the batch sorption experiments showed that the sorption of all test chemicals to PTFE was negligibly weak. Moreover, the good mass balance obtained indicates that the glass cells used do not significantly sorb the four test chemicals. By fitting eq $5, k$ was obtained for the sorptive chemicals through PTFE. The resulting $k$ values fall around the $k$ vs $D_{\mathrm{w}}$ regression obtained with the nonsorptive chemicals (Figure 4), which indicates that the overall rate of mass transfer through the PTFE filter is determined by the diffusive mass transfer through the ABLs and the membrane pores for all tested chemicals.

Numerical modeling for PES filter permeation. The numerical model used in this study considers the steady-state mass transfer through the two ABLs, the diffusion through water-filled membrane pores, and the sorption to the MF polymer matrix. A linear sorption isotherm and local sorption equilibrium were assumed. The $K_{\mathrm{PES} / \mathrm{w}}$ value at the estimated final equilibrium concentration in the permeation experiment 
was interpolated with the Freundlich model (Table 1) and used as an input parameter for modeling. $d_{\mathrm{ABL}}$ was set to $88 \mu \mathrm{m}$.

Figure $3 \mathrm{C}$ and $3 \mathrm{E}$ show that the model well approximates the results of the permeation experiments for the sorptive chemicals. Assuming linear and equilibrium sorption is a simplification, contradicting the results of batch sorption experiments (i.e., nonlinear isotherms, slow equilibration) in a strict sense. The good model performance suggests that such simplifications do not cause large errors at least in short-term modeling. It is encouraging that the decreasing donor concentrations for strongly sorbing indole and 2methoxyInaphthalene are well predicted by the model. As the PES filter sorbs these chemicals strongly, the bulk surface of the MF (i.e., the first layer that faces the donor solution) serves as an effective sink, and as such, the rate of decrease in the donor concentration is largely determined by the ABL transfer (and not by diffusion in MF pores). Thus, the good agreement between model results and data for the strongly sorbing also adequate.

A noticeable discrepancy between the model and data is some underestimation of the measured acceptor side concentrations for indole in the 36h experiment (Figure 3E). Incorporating the Freundlich equation in the numerical model (see SI-3) resulted in no difference from the linear sorption isotherm (Figure S5). A possible explanation for the observed underestimation is that the instantaneous sorption

Implications for passive sampling practices. The experimental and modeling results shown above

372 has important implications for practices of aqueous passive sampling. The commonly used PES filter is a rather strong sorbent and can cause delayed permeation for many chemicals. The permeation behavior

374 through the PES filter is well approximated by a combination of the ABL transfer, the diffusion through water-filled pores, and the local equilibrium sorption to the PES matrix from porewater, at least for modeling of the short-term permeation behavior. This knowledge should be useful to develop a mathematical model for the sampling behavior by POCIS and Chemcatcher. Minor but significant isotherm nonlinearity of the 
sorption by PES suggests that laboratory calibration experiments should be conducted in the field-relevant concentration range. Moreover, some chemicals including highly hydrophilic ones undergo slow, long-lasting sorption by PES. Influences of sorption kinetics to PES on the permeation behavior in a longer term (i.e., weeks) were not studied in this work and could be a topic of future research.

That being said, all these complicated issues related to the sorption to PES can be avoided by simply replacing the PES with the PTFE filter. The sorption of organic chemicals to PTFE is generally weak, as is wellknown and was also demonstrated in this work. With the PTFE filter, the permeation behavior is simply determined by the $A B L$ transfer and the membrane pore diffusion. In this case, the simple first-order steadystate diffusion model can be used to calculate the flux through the MF. Also to avoid lag-times and slow responses to fluctuating concentrations, we recommend the PTFE filter for aquatic integrative passive sampling in future work. Disadvantages of the used PTFE filter may be its somewhat higher price, smaller thickness (i.e., $R_{\mathrm{s}}$ more susceptible to the $\mathrm{ABL}$ thickness), and far less accumulation of data and experience than PES. However, the cost for MFs should be rather small compared to that of the whole monitoring campaign. ${ }^{19}$ Small thickness can be overcome by stacking multiple filters or using a thicker filter. Data and experience should be collected and shared from now on to exploit the full potential of PTFE filters. To establish a mechanistic model for the whole POCIS and Chemcatcher devices, we additionally need to know the sorption and permeation behavior in the sorbent layer. The same applies to developing $R_{\mathrm{s}}$ prediction models. We are currently working on characterizing the properties of sorbent materials, which will hopefully elucidate the full picture of the chemical uptake and release by aquatic passive samplers.

\section{Associated content}

\section{Supporting Information}

Properties of test chemicals, analytical methods, extended model descriptions, modeling of sorption kinetics, PP-LFER analysis, six tables and five figures. This material is available free of charge via the Internet at http://pubs.acs.org. 
403 Corresponding author

404 ORCID: 0000-0001-8702-1602

405 Satoshi Endo

406 Notes

407 The authors declare no competing financial interest.

\section{Acknowledgements}

409 The authors greatly acknowledge the financial support from Kurita Water and Environment Foundation 410 (15A057) and from the MEXT/JST Tenure Track Promotion Program. Norihiro Watanabe is thanked for his 411 helpful support in modeling and Ikue Okuda for her technical assistance.

\section{References}

413 1. Vrana, B.; Allan, I. J.; Greenwood, R.; Mills, G. A.; Dominiak, E.; Svensson, K.; Knutsson, J.; Morrison, G., 414 Passive sampling techniques for monitoring pollutants in water. Trends Anal. Chem. 2005, 24, (10), $415 \quad 845-868$.

416 2. Harman, C.; Allan, I. J.; Vermeirssen, E. L. M., Calibration and use of the polar organic chemical integrative sampler-A critical review. Environ. Toxicol. Chem. 2012, 31, (12), 2724-2738.

418 3. Miège, C.; Mazzella, N.; Allan, I.; Dulio, V.; Smedes, F.; Tixier, C.; Vermeirssen, E.; Brant, J.; O’Toole, S.; 419 Budzinski, H.; Ghestem, J.-P.; Staub, P.-F.; Lardy-Fontan, S.; Gonzalez, J.-L.; Coquery, M.; Vrana, B., 420 Position paper on passive sampling techniques for the monitoring of contaminants in the aquatic environment - Achievements to date and perspectives. Trends Environ. Anal. Chem. 2015, 8, 20-26. 
422 4. Charriau, A.; Lissalde, S.; Poulier, G.; Mazzella, N.; Buzier, R.; Guibaud, G., Overview of the Chemcatcher ${ }^{\circledast}$ for the passive sampling of various pollutants in aquatic environments Part $A$ : Principles, calibration, preparation and analysis of the sampler. Talanta 2016, 148, 556-571.

425 5. Fauvelle, V.; Mazzella, N.; Delmas, F.; Madarassou, K.; Eon, M.; Budzinski, H., Use of Mixed-Mode lon Exchange Sorbent for the Passive Sampling of Organic Acids by Polar Organic Chemical Integrative Sampler (POCIS). Environ. Sci. Technol. 2012, 46, (24), 13344-13353.

6. Moschet, C.; Vermeirssen, E. L. M.; Singer, H.; Stamm, C.; Hollender, J., Evaluation of in-situ calibration of Chemcatcher passive samplers for 322 micropollutants in agricultural and urban affected rivers. Water Res. 2015, 71, 306-317.

7. Belden, J. B.; Lotufo, G. R.; Biedenbach, J. M.; Sieve, K. K.; Rosen, G., Application of POCIS for Exposure Assessment of Munitions Constituents during Constant and Fluctuating Exposure. Environ. Toxicol.

8. Harman, C.; Brooks, S.; Sundt, R. C.; Meier, S.; Grung, M., Field comparison of passive sampling and biological approaches for measuring exposure to PAH and alkylphenols from offshore produced water discharges. Mar. Pollut. Bull. 2011, 63, (5-12), 141-148.

9. Vermeirssen, E. L. M.; Bramaz, N.; Hollender, J.; Singer, H.; Escher, B. I., Passive sampling combined with ecotoxicological and chemical analysis of pharmaceuticals and biocides - Evaluation of three Chemcatcher ${ }^{\mathrm{TM}}$ configurations. Water Res. 2009, 43, (4), 903-914.

10. Tiam, S. K.; Fauvelle, V.; Morin, S.; Mazzella, N., Improving Toxicity Assessment of Pesticide Mixtures: The Use of Polar Passive Sampling Devices Extracts in Microalgae Toxicity Tests. Front. Microbiol. 2016, 7.

11. Poulier, G.; Lissalde, S.; Charriau, A.; Buzier, R.; Delmas, F.; Gery, K.; Moreira, A.; Guibaud, G.; Mazzella, N., Can POCIS be used in Water Framework Directive (2000/60/EC) monitoring networks? A study focusing on pesticides in a French agricultural watershed. Sci. Total Environ. 2014, 497, 282-292. 
12. Alvarez, D. A.; Petty, J. D.; Huckins, J. N.; Jones-Lepp, T. L.; Getting, D. T.; Goddard, J. P.; Manahan, S. E., Development of a passive, in situ, integrative sampler for hydrophilic organic contaminants in aquatic environments. Environ. Toxicol. Chem. 2004, 23, (7), 1640-1648.

13. Kingston, J. K.; Greenwood, R.; Mills, G. A.; Morrison, G. M.; Persson, L. B., Development of a novel passive sampling system for the time-averaged measurement of a range of organic pollutants in aquatic environments. J. Environ. Monit. 2000, 2, (5), 487-495.

14. Vermeirssen, E. L. M.; Dietschweiler, C.; Escher, B. I.; van der Voet, J.; Hollender, J., Transfer Kinetics of Polar Organic Compounds over Polyethersulfone Membranes in the Passive Samplers POCIS and Chemcatcher. Environ. Sci. Technol. 2012, 46, (12), 6759-6766.

15. Vermeirssen, E. L. M.; Dietschweiler, C.; Escher, B. I.; van der Voet, J.; Hollender, J., Uptake and release kinetics of 22 polar organic chemicals in the Chemcatcher passive sampler. Anal. Bioanal. Chem. 2013, $405,(15), 5225-5236$.

16. Tran, A. T. K.; Hyne, R. V.; Doble, P., Calibration of a passive sampling device for time-integrated sampling of hydrophilic herbicides in aquatic environments. Environ. Toxicol. Chem. 2007, 26, (3), 435443.

17. Harman, C.; Tollefsen, K. E.; Boyum, O.; Thomas, K.; Grung, M., Uptake rates of alkylphenols, PAHs and carbazoles in semipermeable membrane devices (SPMDs) and polar organic chemical integrative samplers (POCIS). Chemosphere 2008, 72, (10), 1510-1516.

18. Silvani, L.; Riccardi, C.; Eek, E.; Papini, M. P.; Morin, N. A. O.; Cornelissen, G.; Oen, A. M. P.; Hale, S. E., Monitoring alkylphenols in water using the polar organic chemical integrative sampler (POCIS): Determining sampling rates via the extraction of PES membranes and Oasis beads. Chemosphere 2017, $184,1362-1371$.

19. Petrie, B.; Grayell, A.; Mills, G. A.; Youdan, J.; Barden, R.; Kasprzyk-Hordern, B., In Situ Calibration of a New Chemcatcher Configuration for the Determination of Polar Organic Micropollutants in Wastewater Effluent. Environ. Sci. Technol. 2016, 50, (17), 9469-9478. 
20. Kuster, M.; De la Cal, A.; Eljarrat, E.; de Alda, M. J. L.; Barcelo, D., Evaluation of two aquatic passive

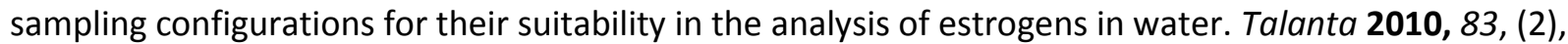
493-499.

21. Shaw, M.; Mueller, J. F., Time Integrative Passive Sampling: How Well Do Chemcatchers Integrate Fluctuating Pollutant Concentrations? Environ. Sci. Technol. 2009, 43, (5), 1443-1448.

22. Schäfer, R. B.; Paschke, A.; Liess, M., Aquatic passive sampling of a short-term thiacloprid pulse with the Chemcatcher: Impact of biofouling and use of a diffusion-limiting membrane on the sampling rate. J. Chromatogr. A 2008, 1203, (1), 1-6.

23. Mazzella, N.; Dubernet, J. F.; Delmas, F., Determination of kinetic and equilibrium regimes in the operation of polar organic chemical integrative samplers - Application to the passive sampling of the polar herbicides in aquatic environments. J. Chromatogr. A 2007, 1154, (1-2), 42-51.

24. Miller, T. H.; Baz-Lomba, J. A.; Harman, C.; Reid, M. J.; Owen, S. F.; Bury, N. R.; Thomas, K. V.; Barron, L. P., The First Attempt at Non-Linear in Silico Prediction of Sampling Rates for Polar Organic Chemical Integrative Samplers (POCIS). Environ. Sci. Technol. 2016, 50, (15), 7973-7981.

25. Shaw, M.; Eaglesham, G.; Mueller, J. F., Uptake and release of polar compounds in SDB-RPS Empore ${ }^{\mathrm{TM}}$ disks; implications for their use as passive samplers. Chemosphere 2009, 75, (1), 1-7.

26. Harman, C.; Allan, I. J.; Bauerlein, P. S., The Challenge of Exposure Correction for Polar Passive Samplers-The PRC and the POCIS. Environ. Sci. Technol. 2011, 45, (21), 9120-9121.

27. Krylov, S. N.; Dunford, H. B., Accelerating Effect of Umbelliferone on Peroxidase-Catalyzed Oxidation of Indole-3-acetic Acid at Neutral pH. J. Phys. Chem. 1996, 100, (50), 19719-19727.

28. Li, J.; Zhang, Q. C.; Zhang, Y. J.; Wei, Q.; Sun, S. D.; Zhao, C. S., Polyethersulfone nanofibers for the removal of endocrine disruptors. Desalin. Water Treat. 2011, 29, (1-3), 158-163.

29. Doulia, D. S.; Anagnos, E. K.; Liapis, K. S.; Klimentzos, D. A., Removal of pesticides from white and red wines by microfiltration. J. Hazard. Mater. 2016, 317, 135-146.

30. Abraham, M. H.; Ibrahim, A.; Zissimos, A. M., Determination of sets of solute descriptors from chromatographic measurements. J. Chromatogr. A 2004, 1037, (1-2), 29-47. 
497 31. Endo, S.; Goss, K.-U., Applications of Polyparameter Linear Free Energy Relationships in Environmental $498 \quad$ Chemistry. Environ. Sci. Technol. 2014, 48, (21), 12477-12491.

499 32. Cussler, E. L., Diffusion: Mass Transfer in Fluid Systems 3rd ed. Cambridge University Press: Cambridge, 5002009

501 33. Lohmann, R., Critical Review of Low-Density Polyethylene's Partitioning and Diffusion Coefficients for 502 Trace Organic Contaminants and Implications for Its Use As a Passive Sampler. Environ. Sci. Technol. $503 \quad 2012,46,(2), 606-618$. 